\title{
Relation between statistics and treatment-related changes obtained from toxicity studies in rats: if detected a significant difference in low or middle dose for quantitative values, this change is considered as incidental change?
}

\author{
Katsumi Kobayashi', Yuki Sakuratani1, Takemaru Abe', Satoshi Nishikawa', Jun Yamada1, \\ Akihiko Hirose ${ }^{2}$, Eiichi Kamata² and Makoto Hayashi1,3

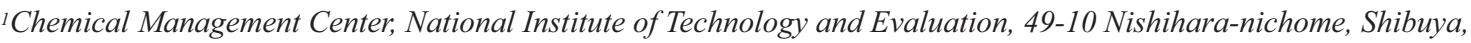 \\ Tokyo 151-0066, Japan \\ ${ }^{2}$ National Institute of Health Sciences, 18-1 Kamiyoga-ichome, Setagaya-ku, Tokyo 158-8501, Japan \\ ${ }^{3}$ An-Pyo Center, 582-2 Shioshinden, Iwata-shi, Shizuoka 437-1213, Japan
}

(Received October 8, 2009; Accepted November 11, 2009)

\begin{abstract}
The purpose of a toxicity test is to determine the no-observed-effect level (NOEL) of test substance through biological and pharmacological techniques. If the low dose not does show statistically significant and biologically relevant changes in the data evaluated in a study, the usual practice is to consider this dose as the NOEL. To overcome this, 6 types of techniques that seemed to be appropriate are presented in this paper by investigating the results of several domestic and foreign theses on toxicology. The most appropriate techniques appear to be the trend test, comparison between treatment group and historical control by $t$-test, and confirmation that all individual values lie within the $95 \%$ confidence interval (2 SD) of the historical control value, if a significant difference is admitted in the low dose.
\end{abstract}

Key words: Toxicity, Rodents, Statistics, Historical control data, Incidental change, Standard deviation and error

\section{INTRODUCTION}

Toxicity test is necessary for evaluating the safety of industrial chemicals according to the Chemical Substances Control Law (1986). Quantitative data obtained from toxicity studies with test substance in rodents are analyzed by using decision tree procedure (Hamada et al., 1998; Kobayashi et al., 2008). If statistical analysis of such data reveals that low or mid dose data are significantly different as compared to the control group used as a reference for that particular study, it may not be possible to determine the no-observed-effect level (NOEL) of that test substance. This significant difference obtained in the low and mid dose groups is usually not considered as incidental. This can be confirmed by comparing the data of these groups with the historical control data obtained from the testing facilities or by confirming that there was no dose-related pattern observed, statistically or visually. Usually the comparison with the historical control data is made by checking the data of the treatment groups (low and mid dose), whether they lie within the width of 2 standard deviations (S.D.) of the historical control data. If the data of the treatment groups lie within the width of 2 S.D. of the historical control, it is assumed that the changes shown by these groups are incidental. However, the S.D. plotted shows the distribution pattern of all the individual historical control data, whereas the data of the treatment group is obtained by calculating the mean of 5 to 35 animals used in an experiment. Hence, the comparison between these 2 data sets may be erroneous since the quality of data of both the groups is different. In order to resolve these disagreements and to confirm incidental finding, this paper presents six alternative techniques. We would have liked to have documented the uniformity of each testing facility in the form of a thesis; however, the documentation of this kind is problematic since there are restrictions in publishing the toxicity results of a non-government organization and since the investigation

Correspondence: Katsumi Kobayashi (E-mail: kobayashi-katsumi@nite.go.jp) 
of the problem are difficult.

\section{Techniques for confirming an incidental finding}

\section{Examination of dose-response pattern and/or dose dependency}

In a study, when a significant difference is obtained only for the low dose group and no dose-response relationship is observed, it is judged as an incidental finding, visually. Statistical tests such as the Jonckheere trend test (Jonckheere, 1954), which is designed for the quantitative evaluation of the body weight, hematological values, and organ weights and the Cochran-Armitage trend test, which is designed for the qualitative analysis of urine samples and for pathological data, can be used to confirm the incidental finding. If no significant difference is obtained between the treatment and the control groups by these tests, then the result is considered as an incidental change. Jonckheere's trend test (http://dra4.nihs. go.jp/mhlw_data/home/paper/paper86-87-3b.html and http://dra4.nihs.go.jp/mhlw_data/home/paper/paper9564-7B.html) is the ideal test for analyzing the results of a study involving a 28-day dosing-period in accordance with the Chemical Substance Control Law (1986).

\section{Williams's test wherein dosage dependency is considered}

William's test (Williams, 1971, 1972) is a technique for analyzing dose-dependent responses. In this test, if significant difference is observed in low-dose group and not in the high-dose group, then the change is considered to be incidental. This technique is termed "closed testing procedure," and this method was used by Sakaki et al. (2000) for constructing the decision tree.

\section{Comparison with related measurement items}

In this method, items with relative measurements are compared, for example, expression of glutamic oxaloacetic transaminase (GOT) is compared with that of glutamic pyruvic transaminase (GPT); the red blood count analysis, hemoglobin value, hematocrit value, and erythrocyte indices (mean corpuscular volume (MCV), mean corpuscular hemoglobin $(\mathrm{MCH})$, and mean cell hemoglobin concentration (MCHC)) are compared; and the organ weight is compared with the pathological findings. An overall judgment is made by these comparisons.

\section{Comparison with the historical control data (in cases} where the number of animal used is clearly mentioned)

This test can be used to determine whether or not the mean value of the low dose group falls within the width of 2 standard error values ( \pm 2 S.E.; $95 \%$ confidence interval for the mean) of the historical control value. It can also be used to determine whether or not all the individual values of a treatment group fall within the width of \pm 2 S.D. of the historical control data.

(1) Using the above test, it can be concluded that there is no significant difference if the mean value of the treatment group lies within the width of \pm 2 S.E. values of the historical control value (Table 1 ) and

(2) If all the individual values of the treatment group

Table 1. Comparison of low and mid dose data with historical control data of 28-day repeated dose toxicity studies in rats (Source: Chemical Substances Control Law)

\begin{tabular}{|c|c|c|c|c|c|c|c|}
\hline \multirow[b]{2}{*}{ Cas No. } & \multirow[b]{2}{*}{ Parameters } & \multirow{2}{*}{$\frac{\text { Result of toxicity study (1) }}{\text { Mean } \pm \text { S.D. (Dose level) }}$} & \multicolumn{3}{|c|}{ Historical control data (2) } & \multirow{2}{*}{$\begin{array}{c}\text { Judgment } \\
\text { Within range } \\
\pm 2 \text { S.E. }\end{array}$} & \multirow{2}{*}{$\begin{array}{l}P \text { value by } \\
t \text {-test } \\
\text { (1) vs. (2) }\end{array}$} \\
\hline & & & Mean \pm S.D. (N) & $\begin{array}{l}\text { Range of } \\
\pm 2 \text { S.D. }\end{array}$ & $\begin{array}{l}\text { Range of } \\
\pm 2 \text { S.E. }\end{array}$ & & \\
\hline \multirow{2}{*}{$97-52-9$} & GPT (U) & $16 \pm 4^{*}($ high $)$ & $15 \pm 9(60)$ & 33-0 & $17.3-12.7$ & Yes & 0.807 \\
\hline & SG in urine & $1.046 \pm 0.012^{*}$ (high) & $1.065 \pm 0.028(60)$ & $1.121-1.009$ & $1.072-1.058$ & No & 0.139 \\
\hline 7756-94-7 & $\begin{array}{l}\text { Adrenal weights } \\
(\mathrm{mg})\end{array}$ & $\begin{array}{l}49 \pm 9^{*} \text { (low) } \\
48 \pm 9^{*} \text { (mid) } \\
46 \pm 6^{*} \text { (high) }\end{array}$ & $53 \pm 7(40)$ & $67-39$ & $55.2-50.8$ & No & $\begin{array}{l}0.248 \\
0.150 \\
0.038\end{array}$ \\
\hline $526-73-8$ & $\begin{array}{l}\text { White blood cell } \\
\text { count }\left(10^{3} / \mathrm{mm}^{3}\right)\end{array}$ & $\begin{array}{l}10.9 \pm 2.8^{*}(\text { low }) \\
11.0 \pm 2.6^{*}(\text { mid }) \\
14.0 \pm 4.5^{*}(\text { high })\end{array}$ & $11.8 \pm 3.5(80)$ & $18.8-4.8$ & $12.6-11.2$ & No & $\begin{array}{l}0.575 \\
0.617 \\
0.183\end{array}$ \\
\hline \multirow[t]{2}{*}{$56-93-9$} & $\begin{array}{l}\text { Platelet count } \\
\left(10^{3} / \mathrm{mm}^{3}\right)\end{array}$ & $1187 \pm 107^{*}$ (high) & $1103 \pm 124(50)$ & $1351-855$ & $1138-1068$ & No & 0.150 \\
\hline & Total protein $(\mathrm{g} / \mathrm{dl})$ & $5.44 \pm 0.15^{*}$ (high) & $5.66 \pm 0.2(50)$ & $6.06-5.26$ & $5.72-5.60$ & No & 0.020 \\
\hline
\end{tabular}

${ }^{*} P<0.05$ from concurrent control group.

\# $95 \%$ confidence interval of the mean. 
Relation between statistics and NOEAL obtained from toxicity test

lie within the width of \pm 2 S.D. of the historical control value (Fig. 1).

(3) Also the difference between the mean value of the historical control group and that of the treatment group is analyzed by the $t$-test (Table 1 ).

\section{The NOEL judgments}

The NOEL is judged by the study director on the basis of his/her knowledge and experience in addition to the data presented in the thesis. In this case, priority may be given to the clinical relevance of the data as compared to the statistical significant difference. For instance, a significant difference might be detected by using statistics when considering parameters that have a small variance, such as the electrolyte concentration or specific gravity of urine samples. In this case, statistical results are ignored, and the clinical relevance is considered.

\section{Checking the reliability of the control group}

It is sometimes necessary to check whether or not the control group used in a study is in the normal range. The comparison of the treatment group with double controls (usually used in basal diet experiments) is also made by statistical analysis. Alternatively, the control group can be compared with the historical control value.

\section{Investigation using published studies}

\section{8-day repeated dosing study in accordance with the Chemical Substance Control Law}

The examples of the 28-day repeated dose toxicity study in rats are available in the public domain (http:// dra4.nihs.go.jp/mhlw_data/jsp/SearchPage.jsp) and are presented in Table 1.

When the data of the treatment groups were compared with the historical data, it was found that the mean values

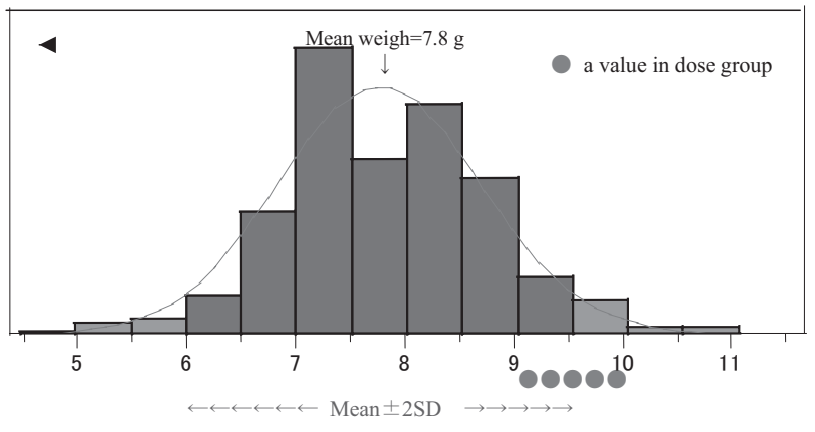

Fig. 1. Is there an individual of the examination group within mean \pm 2 S.D. of the historical value? of the treatment groups were within the range of \pm 2 S.D. of the historical control data, but not within the range of \pm 2 S.E. of it (except GPT of CAS No. 97-52-9) (Table 1). In the above studies, the authors judged whether the significant differences shown by the treatment groups were incidental or not by examining the data of the treatment groups with regard to the range of \pm 2 S.E. of the respective historical control data. If the data of the treatment groups fall within the range of \pm 2 S.E. of the historical control, they were considered as incidental. However, when the data were analyzed using $t$-test, adrenal weight (CAS No. 7756-94-7) and total protein (CAS No. 56-939) of the high dose were significant. Though the calculation procedure of $t$-test is based on the SEs of the treatment and historical control groups, it should be borne in mind that the number of animals used in these groups is different, being much larger in the latter, since the source of historical control data is several studies. But, while comparing the values within the range of the standard error, the number of animals used in each group is not taken into consideration.

In the repeated dose toxicity studies, when a significant difference between the treated and control values is detected at the low or medium doses, the determination of NOEL is difficult. An attempt was made to find out a solution to this problem by investigating 28-day repeat dose toxicity gavage studies in Sprague-Dawley (SD) rats wherein 126 test substances were analyzed in accordance with the Chemical Substance Control Law guidelines (http://dra4.nihs.go.jp/mhlw_data/jsp/SearchPage.jsp) (Table 2). Among the studies investigated, only one testing facility in Japan described historical control mean value \pm S.D. and the number of animals clearly in the report. The statements, such as "No dose-related pattern or dose dependency", made in the reports clearly show that there is no significant difference in the high and/or medium dose groups. It seems that the dose-response pattern and/ or the dose dependency in most of the studies have been evaluated solely by a macroscopic decision. The following or similar statement from several report, supports our view, "this change was within the physiological range and/or the historical control range or is minimal change." In these reports, the authors have not given the range of values for the historical controls. Thus, the study director assumed that the change in this dosage group to be an incidental change without a statistics or solid scientific support.

\section{Studies published in journals}

On investigating the changes of parameters of dosage groups of several repeated dose toxicity studies in rodents 
Table 2. Number of repeated-dose toxicity studies from different testing facilities, in which changes shown by the treated groups were not attributed to the test substance, though these groups showed a statistical significant difference compared to historical control

\begin{tabular}{|c|c|c|c|c|c|c|c|c|c|c|}
\hline \multirow[b]{2}{*}{ Reason for no toxicological effect } & \multicolumn{9}{|c|}{ Testing facility (no. of study) } & \multirow{2}{*}{$\begin{array}{l}\text { Total } \\
(126)\end{array}$} \\
\hline & $\begin{array}{c}\text { PA } \\
(10)\end{array}$ & $\begin{array}{l}\text { BO } \\
(12)\end{array}$ & $\begin{array}{c}\text { SE } \\
(15)\end{array}$ & $\begin{array}{l}\text { NI } \\
(3)\end{array}$ & $\begin{array}{c}\text { MI } \\
(18)\end{array}$ & $\begin{array}{l}\text { AN } \\
(22)\end{array}$ & $\begin{array}{l}\mathrm{FO} \\
(23)\end{array}$ & $\begin{array}{l}\mathrm{RE} \\
(14)\end{array}$ & $\begin{array}{l}\text { NB } \\
(9)\end{array}$ & \\
\hline $\begin{array}{l}\text { No change in a related parameter and no } \\
\text { toxicological significant difference }\end{array}$ & 2 & 1 & 5 & 0 & 6 & 5 & 6 & 0 & 1 & 26 \\
\hline $\begin{array}{l}\text { Within physiological (historical) range, negligible } \\
\text { or sporadic change }\end{array}$ & 7 & 0 & 3 & 0 & 8 & 9 & 3 & 3 & 5 & 38 \\
\hline $\begin{array}{l}\text { Within historical control range (mean } \pm 2 \text { S.D. }) \text {, } \\
{[\text { displayed mean } \pm \text { S.D. and } \mathrm{N}]}\end{array}$ & 0 & 0 & 0 & 0 & 0 & 7 & 0 & 0 & 0 & 7 \\
\hline $\begin{array}{l}\text { No dose-related pattern or no dose-dependence, } \\
\text { visually }\end{array}$ & 3 & 10 & 5 & 1 & 7 & 14 & 16 & 8 & 2 & 66 \\
\hline $\begin{array}{l}\text { Change in narrow range compared to control } \\
\text { group or historical control values }\end{array}$ & 0 & 0 & 2 & 0 & 0 & 0 & 1 & 0 & 0 & 3 \\
\hline $\begin{array}{l}\text { Significant difference only in males or females or } \\
\text { a significant difference only in right or left organ }\end{array}$ & 0 & 0 & 0 & 0 & 1 & 0 & 2 & 0 & 0 & 3 \\
\hline
\end{tabular}

published in native and foreign journals, we found that in many of the studies the changes were considered as incidental using certain assumptions. The assumptions used were, "There was no dose-related pattern or there was no dosage dependency", "lack of a significant biological difference, a negligible change, a change within physiological range or a sporadic change, etc." (Table 3). In these reports, it has not been mentioned whether it is the mean value or an individual value of the dose group that has been used for the comparison.

In order to find the changes observed in the dosage groups incidental or not, Cerdá et al. (2003) compared the data of the dosage groups with that of historical control data using $t$-test. The authors also checked whether the data of the dosage groups fall within \pm 2 S.D. of the historical control data. There were many parameters of the dosage groups, for example, the red blood cell counts and erythrocyte indices, serum enzymes, organ weights and the pathological findings which did not fall within \pm 2 S.D. of the historical control data. The authors judged the changes in these parameters as incidental changes due to the reason that there was no difference between related parameters.

\section{Method for the comparison of historical control value and dose group value-Are all individual values considered while distributing the historical control value?}

Taking into consideration 1 of the comparisons between the historical control value and the dose group value, no discrepancies are encountered if all the individual values of the dosage group fall within the $95 \%$ confidence interval of the distribution of the historical control values. The actual assumption is shown in Fig. 1. The figure shows the distribution of the weights of 4-day-old male SD pups (data measured in 2000). The data show that 300 male pups were used; mean \pm S.D. is $7.8 \pm 0.9 \mathrm{~g}$ and the $95 \%$ confidence interval ( \pm 2 S.D.) is 9.6 to 6.0 g. Mean value \pm S.D. of the treatment group used in the study is $9.4 \pm$ 1.2. The mean value of the treatment group is within the 2 S.D. of the background value. However, all the individual pups in the treatment group were not considered while calculating the $95 \%$ confidence interval of the historical control values. Therefore, the treatment group showed deviations from the historical control value.

In conculsion, in such a case, it is generally considered that the test substance does not influence the data of the treatment group, if the mean value of it is included in the width of the mean \pm 2 S.D. of the historical control value. However, it is still impossible to confirm that it is an NOEL in cases where there is no statistical difference noted, even if the mean value of the treatment group is within the width of the standard deviation $( \pm 2$ S.D. $)$ when the distribution curve of individual values is plotted. However, the authors feel that there is a flaw in this technique. Hence, as an alternative to the above method, we propose the following statistical methods for the comparison of dosage groups with historical control values: 
Relation between statistics and NOEAL obtained from toxicity test

Table 3. Grounds considered as incidental changes to the significant differences in dosed group of repeated dose toxicity studies

\begin{tabular}{ll}
\hline Reason assumed to be incidental change & \multicolumn{1}{c}{ Reference } \\
\hline Presence of dose-related pattern, visually & Nishiguchi et al., 1997; Nishiguchi et al., 1994; Takagi et al., 1992b; Nakano et al., \\
& 1992; Tamura et al., 1983; Yamazaki et al., 2005; Chemical product Safety Center, \\
& 1994; Griffiths et al., 2007; Topping et al., 2007; Guijie et al., 2006; Poon et al., \\
& 1998; McClain et al., 2006; Sato et al., 2007; Hellwig et al., 1993; Webb et al., 1993; \\
& Mellert et al., 2002; Bär et al., 1995; Arterburn et al., 2000; Goldsmith, 2000; Lee \\
& et al., 2004; Janssen et al., 2000; Kanki et al., 2003; O'Hagan and Menzel, 2003; \\
& Nakamura et al., 2001; Thomas et al., 1991; Abdo et al., 1986; Morgan et al., 1989; \\
& Dunnick et al., 1987; Okazaki et al., 2002; Okazaki et al., 1993; Kato et al., 1993; \\
& Jeong et al., 2006; Shim et al., 2003
\end{tabular}

No change in a related parameter

Inui et al., 1997; Takeuchi et al., 1985; Jonker et al., 1993; MacKenzie et al., 1992a; Barber and Topping, 1995; Oshima et al., 1999; Suzuki et al., 1997; Graça et al., 2007; Shimpo et al., 1990

High or low value of control group

Inui et al., 1997; Mellert et al., 2002; Macrì et al., 1987

Study director's judgment (no significant biological difference effect, negligible change, within physiological change or sporadic change)

Within historical range (background data) or normal range (not described to macroscopic or statistic significant)

Takagi et al., 1994a; Nakano et al., 1992; Kato et al., 1991; Takahashi et al., 1986; Omosu et al., 2003; Griffiths et al., 2007; Topping et al., 2007; Inui et al., 1997; Cho et al., 2006; MacKenzie et al., 1992a, 1992b; Juberg et al., 1998; Horváth et al., 2002; Kotkoskie et al., 1998; Oshima et al., 1999; Yi et al., 2007

Takahashi et al., 1986; Tamura et al., 1983; Omosu et al., 2003; Griffiths et al., 2007; Guijie et al., 2006; McClain et al., 2006; Horváth et al., 2002; Kitamura et al., 2003; Hart, 1988; Suzuki et al., 1994; Shiraishi et al., 2006

Compared with another control other than vehicle control (using by double control)

Takahashi et al., 1986; Webb et al., 1993; Arterburn et al., 2000

Statistics processing with normal values (historical data) range

Cerdá et al., 2003

1. There is no significant difference if the mean value of if all the individual values of the dosage group fall within mean \pm 2 S.E. for the historical control values.

2. There is no significant difference if all the individual values of the dosage group fall within mean \pm 2 S.D. of the historical control values.

3. The statistical significant difference of the mean values between the dosage and historical control values group may be analyzed using the $t$-test.

4. The dose-response pattern/dose dependency may be analyzed using statistical techniques, for instance, Jonckheere trend test can be applied.

We recommend one in the above-mentioned four techniques to be used. However we suggest that the decision may not be made entirely on the basis of statistical analysis, but biological relevance of the statistical analysis may also be looked into.

\section{ACKNOWLEDGMENTS}

The research described in this paper was supported by a grant (Project name: Development of hazard assessment techniques using structure-activity relationship methods) from the New Energy and Industrial Technology Development Organization (NEDO). We gratefully thank Dr. K. Sadasivan Pillai from Frontier Tissueline Pvt. Ltd. (Chennai, INDIA) for his excellent advice concerning this article.

\section{REFERENCES}

Abdo, K.M., Rao, G., Montgomery, C.A., Dinowitz, M. and Kanagalingam, K. (1986): Thirteen-week toxicity study of d- $\alpha-$ tocopheryl acetate (Vitamin E) in Fischer 344 rats. Food Chem. Toxicol., 24, 1043-1050.

Arterburn, L.M., Boswell, K.D., Koskelo, E., Kassner, S.L., Kelly, C. and Kyle, D.J. (2000): A combined Subchronic (90-day) toxicity and neurotoxicity study of a single-cell source of docosahexaenoic acid triglyceride (DHASCO oil). Food Chem. Toxicol., 38, 35-49.

Bär, A., Til, H.P. and Timonen, M. (1995): Subchronic oral toxicity study with regular and enzymatically depolymerized sodium carboxymethylcellulose in rats. Food Chem. Toxicol., 33, 909-917.

Barber, E.D. and Topping, D.C. (1995): Subchronic 90-day oral tox- 
K. Kobayashi et al.

icology of Di(2-ethylhexyl) terephthalate in the rat. Food Chem. Toxicol., 33, 971-978.

Cerdá, B., Cerón, J.J., Tomás-Barberán, F.A. and Espín, J.C. (2003): Repeated oral administration of high doses of the pomegranate ellagitannin punicalagin to rats for 37 days is not toxic. J. Agric. Food Chem., 51, 3493-3501.

Chemical product Safety Center, Hita research facility (1994): 28day repeated dose oral toxicity study with WAM II. North American HSE SERVICES, September 27, 2007, Test cord No. B110209.

Chemical Substances Control Law (1986): http://www.safe.nite. go.jp/kasinn/genkou/kasinhou04.html

Cho, Y.M., Onodera, H., Ueda, M., Imai, T. and Hirose, M. (2006): A 13-week Subchronic toxicity study of dietary administered morin in F344 rats. Food Chem. Toxicol., 44, 891-897.

Dunnick, J.K., Jameson, C.W. and Montgomery, C.A. (1987): Subchronic toxicity of propantheline bromide administered in the feed to Fischer 344/N rats and B6C3F1 mice. Fundam. Appl. Toxicol., 9, 496-503.

Goldsmith, L.A. (2000): Acute and Subchronic toxicity of sucralose. Food Chem. Toxicol., 38, S53-S69.

Graça, C., Baggio, C.H., Freitas, C.S., Rattnann, Y.D., de Souza, L.M., Cipriani, T.R., Sassaki, G.L., Rieck, L., Pontarolo, R., da Silva-Santos, J.E. and Marques, M.C. (2007): In vivo assessment of safety and mechanisms underlying in vitro relaxation induced by Mikania laevigata Schultz Bip. ex Baker in the rat trachea. J. Ethnopharmacol., 112, 430-439.

Griffiths, J.C., Borzelleca, J.F. and St. Cyr, J. (2007): Sub-chronic (13-week) oral toxicity study with D-ribose in Wistar rats. Food Chem. Toxicol., 45, 144-152.

Guijie, F., Oinghua, H., Shiqi, Z., Daju, W., Yanling, Z. and Zonghui, Y. (2006): Subchronic oral toxicity study with cyadon in Wister rats. Food Chem. Toxicol., 44, 36-416.

Hamada, C., Yoshino, K., Matsumoto, K., Nomura, M. and Yoshimura, I. (1998): Tree-type algorithm for statistical analysis in chronic toxicity studies. J. Toxicol. Sci., 23, 173-181.

Hart, J.E. (1988): Subacute toxicity of diethylstilboestrol and hexoestrol in the female rat, and the effects of clomiphene pretreatment. Food Chem. Toxicol., 26, 227-232.

Hellwig, J., Deckardt, K. and Freisberg, K.O. (1993): Subchronic and chronic studies of the effects of oral administration of acrylic acid to rats. Food Chem. Toxicol., 31, 1-18.

Horváth, K., Noker, P.E., Somfai-Relle, S., Glávits, R., Financsek, I. and Schauss, A.G. (2002): Toxicity of methylsulfonylmethane in rats. Food Chem. Toxicol., 40, 1459-1462.

Inui, T., Fujiwara, T., Susami, M., Hishida, N., Kuwamura, Y., Kise, H., Kawai, Y. and Kudo, S. (1997): Repeated dose toxicity studies of taltirelin tetrahydrate (TA-0910) by oral administration to rats. J. Toxicol. Sci., 22, Suppl. 2, 335-356.

Janssen, G.B., Beems, R.B.H., Elvers, L.H. and Speijers, G.J.A. (2000): Subchronic toxicity of $\alpha$-ergocryptine in Sprague-Dawley rats. 2: metabolic acid and hormonal changes. Food Chem. Toxicol., 38, 689-695.

Jeong, S.H., Kim, B.Y., Kang, H.G., Ku, H.O. and Cho, J.H. (2006): Effect of chlorpyrifos-methyl on steroid and thyroid hormones in rat F0- and F1-generations. Toxicology, 220, 189-202.

Jonckheere, A.R. (1954): A distribution-free k-sample test against ordered alternatives. Biometrika, 41, 133-145.

Jonker, D., Woutersen, R.A., van Bladeren, P.J., Til, H.P. and Feron, V.J. (1993): Subacute (4-wk) oral toxicity of a combination of four nephrotoxins in rats: comparison with the toxicity of the individual compounds. Food Chem. Toxicol., 31, 125-136.
Juberg, D.R., David, R.M., Katz, G.V., Bernaed, L.G., Gordon, D.R., Vlaovic, M.S. and Topping, D.C. (1998): 2-ethylhexanoic acid: Subchronic oral toxicity studies in the rat and mouse. Food Chem. Toxicol., 36, 429-436.

Kanki, K., Nishikawa, A., Furukawa, F., Kitamura, Y., Imazawa, T., Unemura, T. and Hirose, M. (2003): A 13-week Subchronic toxicity study of paprika color in F344 rats. Food Chem. Toxicol., 41, 1337-1343.

Kato, M., West, H.A., Ashby, R., Virgo, D.M., Fowler, J.S.L., Furuhama, K. and Takayama, S. (1991): Four-week sub-acute toxicity study of S-(-)-9-fluoro-2,3-dihydro-3-methyl-10-(4methyl-1-piperazinyl)-7-oxo-7H-pyrido- $[1,2,3,-\mathrm{DE}][1,4]$ benzoxazine-6-carboxylic acid hemihydrate (DR-3355) in CD rats and cynomolgus monkeys. J. Toxicol. Sci., 16, 29-48.

Kato, T., Nakajima, S., Kurihara, H., Asari, A., Sekiguchi, T., Sunose, A., Takahashi, T., Miyauchi, S. and Tokuyasu, K. (1993): Preliminary study for the toxicity study on sodium hyaluronate (Na-HA) in rats by repeated oral administration for 13 weeks. The Clinical Report, 27, 5809-5830.

Kitamura, Y., Nishikawa, A., Furukawa, F., Nakamura, H., Okazaki, K., Umemura, T., Imazawa, T. and Hirose, M. (2003): A subchronic toxicity study of shea nut color in Wistar rats. Food Chem. Toxicol., 41, 1537-1542.

Kobayashi, K., Pillai, K.S., Sakuratani1, Y., Suzuki, M. and Jie, W. (2008): Do we need to examine the quantitative data obtained from toxicity studies for both normality and homogeneity of variance? J. Environ. Biol., 29, 47-52.

Kotkoskie, L.A. and Freeman, C. (1998): Subchronic oral toxicity study of aquacoat ECD ethylcellulose aqueous dispersion in the rat. Food Chem. Toxicol., 36, 705-709.

Lee, K.Y., Shibutani, M., Takagi, H., Arimura, T., Takigami, S., Uneyama, C., Kato, N. and Hirose, N. (2004): Subchronic toxicity study of dietary N-acetylglucosamine in F344 rats. Food Chem. Toxicol., 42, 687-695.

MacKenzie, K.M., Boysen, B.G., Field, W.E. and Petsek, S.R.W. (1992a): Toxicity studies of caramel colour III and 2-acetyl-4(5)tetrahydroxybutylimidazole in F344 rats. Food Chem. Toxicol., 30, 417-425.

MacKenzie, K.M., Carter, J.L. Petsel, S.R., Chappel, C.I., Emerson, J.L. and Stanley, J. (1992b): Subchronic toxicity study of caramel colour II in F344 rats. Food Chem. Toxicol., 30, 411-416.

Macrì, A., Ricciardi, C., Stazi, A.V., Mantovani, A., Macrì, C., Piccioni, A., Badellino, E., Bianchi, M.P., Pepe, M. and Ceccanti, M. (1987): Subchronic oral toxicity of 4-chloro- $\alpha, \alpha, \alpha$-trifluorotoluene in Sprague-Dawley rats. Food Chem. Toxicol., 25, 781786.

McClain, R.M., Wolz, E., Davidovich, A., Pfannkuch, F., Edwards, J.A. and Bausch, J. (2006): Acute, Subchronic and chronic safety studies with genistein in rats. Food Chem. Toxicol., 44, 56-80.

Mellert, W., Deckardt, K., Gembardt, C., Schulte, S., Van Ravenzwaay, B. and Slesinski, R.S. (2002): Thirteen-week oral toxicity study of synthetic lycopene products in rats. Food Chem. Toxicol., 40, 1581-1588.

Morgan, D.L., Jameson, C.W., Mennear, J.H. and Prejeam, J.D. (1989): 14-day and 90-day toxicity studies of C.I. Pigment red 3 in Fischer 344 rats and B6C3F1 mice. Food Chem. Toxicol., 27, 793-800.

Nakamura, H., Furukawa, F., Nishikawa, A., Miyauchi, M., Son, H. Y., Imazawa, T. and Hirose, M. (2001): Oral toxicity of a tocotrienol preparation in rats. Food Chem. Toxicol., 39, 799-805.

Nakano, S., Hayashi, T., Irimura, K., Maruden, A., Nakagawa, K. and Morita, K. (1992): A thirteen-week oral repeated dose tox- 
Relation between statistics and NOEAL obtained from toxicity test

icity study of suplatast tosilate (IPD-1151T) in rats. J. Toxicol. Sci., 17, Suppl. 2, 11-38.

Nishiguchi, Y., Adachi, T., Nakazawa, M., Tawaratani, T., Uchimoto, H., Yoshida, M., Ishibashi, S., Kitayama, E., Iwakura, K. and Sumi, N. (1997): A 13-week oral repeated dose toxicity study of (+/-)-4-diethylamino-1,1-dimethylbut-2-yn-1-yl 2-cyclohexyl-2hydroxy-2-phenylacetate monohydrochloride monohydrate (NS21 ), a novel drug for urinary frequency and incontinence, in rats followed by a 5 -week recovery test. J. Toxicol. Sci., 22, Suppl. 1, 27-57.

Nishiguchi, Y., Ishibashi, S., Tarui, M., Fujimoto, M., Tawaratani, T., Yoshida, M., Uchimoto, H., Adachi, T., Hamasu, Y. and Sumi, N. (1994): 13-week oral toxicity study of lactitol (BS-4) in rats followed by 5 -week recovery test. J. Toxicol. Sci., 19, Suppl. 3, 305-326.

O'Hagan, S. and Menzel, A. (2003): A Subchronic 90-day oral rat toxicity study and in vitro genotoxicity studies with a conjugated linoleic acid product. Food Chem. Toxicol., 41, 1749-1760.

Okazaki, K., Imazawa, T., Nakamura, H., Furukawa, F., Nishikawa, A. and Hirose, M. (2002): A repeated 28-day oral dose toxicity study of 17 alpha-methyltestosterone in rats, based on the "enhanced OECD test guideline 407" for screening the endocrine-disrupting chemicals. Arch. Toxicol., 75, 635-642.

Okazaki, S., Ueno, H., Anabuki, K., Tamura, K., Takeuchi, M., Hasegawa, H. and Kawase, Y. (1993): A 3-month oral toxicity study of MCP-1034 in rats with a recovery period of one month. Jpn. Pharmacol. Ther., 21, 947-974.

Omosu, M., Eluard, B., Thien-A, H., Stepniewski, J.P., Vidal, J.M., Bode, G., Roeder, V., Sacre-Salem, B. and Guffroy, M. (2003): Oral repeated-dose toxicity studies and toxicokinetic studies of telithromycin in rats. Jpn. J. Chemother., 51, 103-114.

Oshima, T., Sugiura, M., Takasu, K., Kimura, M. and Kudo, S. (1999): Repeated dose toxicity study of 3-amino-4-[[(Z)-4[[4-(piperidiomethyl)-2-pyridyl]oxy]-2-butenyl]amino]-3cyclobutene-1,2-dione monohydrochloride (Pibutidine hydrochloride) in rats (1): 13-week oral toxicity study with 4-week recovery test. Jpn. Pharmacol. Ther., 27, 331-345.

Poon, R., Chu, I., Lecavalier, P., Valli, V.E., Foster, W., Gupta, S. and Thomas, B. (1998): Effects of antimony on rats following 90-day exposure via drinking water. Food Chem. Toxicol., 36, 21-35.

Sakaki, H., Igarashi, S., Ikeda, T., Imamizo, K., Omichi, T., Kadota, M., Kawaguchi, T., Takizawa, T., Tsukamoto, O., Terai, K., Tozuka, K., Hirata, J., Handa, J., Mizuma, H., Murakami, M., Yamada, M. and Yokouchi, H. (2000): Statistical method appropriate for general toxicological studies in rats. J. Toxicol. Sci., 25, 71-98.

Sato, S., Kitamura, H., Chino, M., Takei, Y., Hiruma, M. and Nomura, M. (2007): A 13-week oral dose subchronic toxicity study of gardenia yellow containing geniposide in rats. Food Chem. Toxicol., 45, 1537-1544.

Shim, H.J., Kim, Y.C., Jang, J.M., Park, K.J., Kim, D.H., Kang, K. K., Ahn, B.O., Kwon, J.W., Kim, W.B. and Lee, M.G. (2003): Subacute toxicities and toxicokinetics of DA-8159, a new phosphodiesterase type $\mathrm{V}$ inhibitor, after single and 4-week repeated oral administration in rats. Biopharm. Drug Dispos., 24, 409418.

Shimpo, K., Takeuchi, M., Okazaki, S., Kiguchi, M., Hashimoto, Y., Aoki, Y., Kuwata, M. and Yamashita, K. (1990): Three-month oral subacute toxicity study of mofezolac (N-22) in rats. J. Toxicol. Sci., 15, Suppl. 2, 11-41.
Shiraishi, K., Miyata, K., Houshuyama, S., Imatanaka, N., Umano, T., Minobe, Y. and Yamasaki, K. (2006): Subacute oral toxicity study of diethylphthalate based on the draft protocol for "enhanced OECD test guideline no. 407". Arch. Toxicol., 80, 10-16.

Suzuki, S., Ogawa, Y., Kamata, E., Naito, K., Umemura, T., Saito, M., Kaneko, T. and Kurokawa, U. (1994): A 28-day repeated dose toxicity test of Phoxim in Wister rats. Eisei Shikenjo Houkoku, 112, 40-47.

Suzuki, T., Koike, Y., Kitagaki, T. and Yamoto, T. (1997): A 90-day oral repeated dose toxicity study of azelnidipine in rats followed by a 28-day recovery period. Jpn. Pharmacol. Ther., 25, $977-$ 1004 .

Takagi, A., Momma, J., Aida, Y., Takada, K., Suzuki, S., Naitoh, K., Tobe, M., Hasegawa, R. and Kurokawa, Y. (1992): Toxicity studies of a synthetic antioxidant, 2-2'-methylenebis (4-ethyl-6-tertbutylphenol) in rats. 1. Acute and subchronic toxicity. J. Toxicol. Sci., 17, 135-153.

Takagi, A., Takada, K., Sai, K., Ochiai, T., Matsumoto, K., Sekita, K., Momma, J., Aida, Y., Saitoh, M., Naitoh, K., Furuya, T., Hasegawa, R. and Kurokawa, Y. (1994): Acute, Subchronic and chronic toxicity studies of a synthetic antioxidant, 2,2'-methylenebis(4-methyl-6-tert-butylphenol) in rats. J. Toxicol. Sci., 19, $77-88$.

Takahashi, N., Kadota, T., Kawano, S., Ohta, K., Ishikawa, K., Kuroyanagi, K., Hamajima, Y., Ohta, S., Kai, S. and Kohmura, H. (1986): Toxicity studies of VP16-213(II)--Oral one-month subacute toxicity in rats. J. Toxicol. Sci., 11, Suppl. 1, 17-49.

Takeuchi, M., Ichionohe, M., Okazaki, S., Sato, M., Kiguchi, M., Shimpo, K., Sudo, J. and Tanabe, T. (1985): Study on toxicity of halopredone acetate. (II). Subacute toxicity study in rats. J. Toxicol. Sci., 10, Suppl. 1, 11-39.

Tamura, J., Sato, N., Ezaki, H., Miyamoto, H., Oda, S., Hirai, K., Takado, H., Matsumoto, M. and Shirai, T. (1983): Acute toxicity of ranitidine and its metabolite in mice, rats and rabbits, and subacute oral toxicity of ranitidine in rats. J. Toxicol. Sci., 8, Suppl. $1,1-24$

Thomas, W.C., McGrath, L.F., Baarson, K.A., Auletta, C.S., Daly, I.W. and McConnell, R.F. (1991): Subchronic oral toxicity of cellulose acetate in rats. Food Chem. Toxicol., 29, 453-458.

Topping, D.C., Bernard, L.G., O’Donoghue, J.L. and English, J.C. (2007): Hydroquinone: acute and subchronic toxicity studies with emphasis on neurobehavioral and nephrotoxic effects. Food Chem. Toxicol., 45, 70-78.

Webb, D.R., Wood, F.E., Bertram, T.A. and Fortier, N.E. (1993): A 91-day feeding study in rats with caprenin. Food Chem. Toxicol., 31, 935-946.

Williams, D.A. (1971): A test for differences between treatment means when several dose levels are compared with a zero dose control. Biometrics., 27, 103-117.

Williams, D.A. (1972): The comparison of several dose levels with zero dose control. Biometrics., 28, 519-531.

Yamazaki, K., Aiso, S., Matsumoto, M., Arito, H., Nagano, K., Yamamoto, S. and Matsushima, T. (2005): Thirteen-week oral toxicity study of 1,4-dichloro-2-nitrobenzene in rats and mice. Ind. Health, 43, 597-610.

Yi, Y., Yoon, H.J., Kim, B.O., Shim, M., Kin, S.O., Hwang, S.J. and Seo, M.H. (2007): A mixed polymeric micellar formulation of itraconazole: Characteristics, toxicity and pharmacokinetics. J. Control Release, 117, 59-67. 